\title{
The impact of business process management on Job performance
}

\author{
Bassam Fathi Aldiabat \\ Ashraf Bataineh \\ Husam Mahmmud Jamil Abu-Hamour \\ Al-Balqa Applied University, Jordan
}

Keywords

Business process management; employee involvement; information technology; job performance; processes improvement; strategic alignment

\begin{abstract}
The present study aims to examine the impact of business process management on employee's job performance at the Social Security Corporation (SCC). The study's sample consists of (390) employees who will be answering the study's questions and hypotheses. In addition, the researcher developed a questionnaire to detect the impact of business process management on job performance. The most important findings and conclusions of the research are: the arithmetic means of employees' estimates at the SCC towards job performance were moderate and the arithmetic mean of employees' estimates at SCC towards business process management were high too. Regression results indicate there were statistically significant effects for BPM on job performance at the SCC, and process improvement influence came first concerning the size of the effect. The study recommends the SCC to adopt strategic objectives, to increase the concern and interest about IT, and provide electronic services.
\end{abstract}

Corresponding author: Bassam Fathi Aldiabat

Email address for corresponding author: aldaibat@hotmail.com

First submission received: $17^{\text {th }}$ March 2018

Revised submission received: $27^{\text {th }}$ May 2018

Accepted: $14^{\text {th }}$ June 2018

\section{Introduction}

Business process management (BPM) considers relatively one of the new topics in management field, and it connects with the knowledge about running current processes or operations, redesign it in a way that reduce the wasted effort and increase the efficiency, and implement changes in the processes to improve the organizational performance, where it incorporate and merge between the information technology and the processes management structure for the sake of improvement, where the effective management of processes are essential to maximize the value of organizations. Trkman (2010).

Several foreign studies; such as Devika, Sharifah \& Seyed (2016) were conducted to address the business reengineering, and its relationship with several organizational variables. The researcher also noticed shortage in the studies that tried to implement this concept on the Arabic organizations, and therefore this study will provide a realistic view for the SCC level of implementation of the business processes management, and its impact on employees' job performance.

The study problem in its general form connected to the poor realization of relationship between the BPM and employees' job performance, therefore this study seeks to declare the relationship between the BPM and functional performance. The study problems may show through raising the following questions:

- What is the awareness degree about the BPM concepts and its components at the SCC, from the standpoint of employees?

- What are the levels of employees' job performance at the SCC?

- What is the impact of BPM on the employees' job performance at the SCC? 


\section{Literature Review}

\subsection{Business process management (BPM)}

Jiraporn, Christos, James, Tannok \& Pawar (2017) defined business process management (BPM) as a management approach that focuses on the processes, that include four elements: strategic alignment, IT, employees involvement, and processes improvement. Trkman (2010) defined BPM as the efforts that made continuously by the organization to improve the basic activities in it, such as manufacturing, marketing, communications, and the basic elements of organization's processes. According to Chang (2006) BPM is an organizational approach that focuses on the processes, and used in the analysis, design, and development of business processes, to improve the organizational performance and increase the organizational efficiency. Sever (2007) have identified arrange of benefits may expected from adopting BPM, such as improving communications within organizations, identifying inputs, identifying outputs, and business activities clearly, understanding the flow of activities within the organization, until product or service arrive to the customer, improving the decisions related to performance processes follow-up, and improving the individual management. Nadarajah \& Kadir (2013) stated that BPM is one of the important links that integrate between the organizational systems and its human resources, where organizations aim to maximize the efficient use of its resources and achieve its strategic objectives and customers' needs.

Recent studies (e.g., Jiraporn et al, 2017; Asmare, 2012; Hung, 2006) highlight the persuasive and convincing power of business process management on organizational performance. Other studies emphasized the positive impact of using information technology infrastructure on human resources performance (Thabit \& Jmealy,2017; Fakhour, 2016). The exiting studies don't relate BPM and it's components on employee performance. Whereas the current study relates the BPM and it's components on employee performance. Therefore, it was hypothesized that:

First main hypothesis: There is statistically significant impact of business process management on the job performance at level $(a \leq 0.05)$ in the social security corporation.

\subsection{Business process management (BPM) components:}

Models of Business process management have evolved over time and have been a subject of controversy. Kohlbacher \& Hajo (2010) sees that essential elements of BPM are processes documentation, management commitment, process ownership, Process performance measurement, corporate culture in line with the process approach, application of continuous process improvement methodologies, and organizational structure in line with the process approach, while Jiraporn et al(2017) sees that BPM components are strategic alignment, IT, processes-centered, optimization and improvement, and employees involvement. Rosemann \& Brocke (2010) also introduced a model for BPM components, where the organizations that want to achieve the success in implementing the BPM, need to consider six major factors, each item of those contain other secondary factors, which form substantial capability aspects for this concept and these factors include strategic alignment, governance, methods, information technology, individuals, and culture.

From the previous studies, it has been shown that numerous researchers have suggested different BPM components. These different BPM are interrelated. In other words, there are interrelationships that exist among BPM dimensions (Rosemann \& Brocke 2010; Devika et al. 2016; Jeraporn et al.2017; Fakhour 2016). Based on the literature, the common dimensions in all models are the usage of one or more dimensions of Rosemann \& Brocke's model (2010). Particularly, the widespread dimensions include strategic alignment, information technology, process improvement and employee involvement. The four main components are presented as follows.

\subsubsection{Strategic alignment}

Strategic alignment is a core BPM constituent. It involves developing specific strategies to maximize the value from process redesign and improvement. Jiraporn et al. (2017). Organizations must align BPM with the overall strategy of organization, and link between the organizational priorities and organization processes to improve the organizational performance. Hung (2006). According to Sotiris (2000) the most important action in applying BPR is the company's strategic goal to provide customeroriented services. Previous researchers have reported that a well defined strategy is the basis for the 
optimal alignment with the associated-business processes. Rosemann \& Brocke (2010) stated that strategic alignment includes process improvement planning, strategy and process capability linkage, enterprise process architecture, process measure and process customers. According to Neubauer (2009) strategic alignment is one of the major pre-conditions for implementing sustainable BPM. Therefore, we assume that strategic alignment has statistical impact on the job performance.

First secondary hypothesis: There is statistically significant impact of strategic alignment on the job performance at level $(a \leq 0.05)$ in the social security corporation

\subsubsection{Information technology (IT):}

It refers to software, hardware, and information systems that support operational activity, and includes the organization's capabilities related to processes design, processes implementation, processes control and measurement, and processes improvement and innovation. Rhee \& Mehra (2006). According to Chang (2006) information technology can be developed as part of the design-implementation-analysis and improvement of business processes. Sotiris (2000) mentioned that information Technology plays a major role in business process reengineering as it provides office automation, it allows the business to be conducted in different locations, provides flexibility in manufacturing, permits quicker delivery to customers and supports rapid and paperless transactions. In general, it allows an efficient and effective change in the manner in which work is performed. Neubauer (2009) stated that the selection and implementation of appropriate IT-applications is a major pre-condition for efficiently executing corporate business processes. Thus, we assume that information technology has statistical impact on the job performance.

Second secondary hypothesis: There is statistically significant impact of information technology on the job performance at level $(a \leq 0.05)$ in the social security corporation.

\subsection{3 process improvement}

Continuous process improvement refers to sustained incremental improvements of existing processes. Kolache \& Harjo (2010). It includes key elements such as process documentation, value stream mapping, process ownership and process measurement. Smart et al. (2010). Devika et al. (2016) mentioned that organizations implement process improvement for the purpose of addressing the shortcomings identified in their overall performance and to fulfill the need to sustain their competitive advantage. Moreover, Zaire (1999) outlined critical steps in process improvement such as: identification of process customers, understanding of customer requirements, defining output, translation of customer requirements into supplier specifications, defining how the output will be achieved, identification of appropriate measurements, track performance and documenting lessons learnt. Therefore, we assume that process improvement has statistical impact on the job performance.

Third secondary hypothesis: There is statistically significant impact of processes improvement on the job performance at level $(a \leq 0.05)$ in the social security corporation.

\subsection{4 employee involvement:}

Employee involvement means giving employees the ability to do their work: the right information, the right tools, the right training, the right environment, and the authority they need. Sotiris (2000). According to Jeraporn et al. (2017) employee empowerment play crucial role in a BPM. Executive commitment to employee empowerment allows the latter to participate actively. Chen \& Paularj (2004) mentioned that top management must be communicate to employees effectively, setting organizational values to improve organizational performance. Trkman (2010) stated that when workers are empowered to take decisions independently, it may result in smoother operations with lower throughput times. Thus, we assume that employee involvement has statistical impact on the job performance.

Fourth secondary hypothesis: There is statistically significant impact of employees' involvement and incorporation on the job performance at level $(a \leq 0.05)$ in the social security corporation. 


\subsection{Employees job performance:}

According to Hilal (2009) employees' performance means performing the employee to the duties and responsibilities the organization requested or the party that the job associated with, while Ismail (2010) defined it as the employee's ability to achieve the organization goals and objectives. Decenzo \& Robbins (2010) mentioned that employees performance can be measured by using three different systems. Firstly, absolute standards through measuring an employee's performance against established standards. Secondly, relative standards which evaluate an employee's performance by comparing the employee with other employees. Thirdly, use of achieved performance outcomes, where employees are evaluated on how well they accomplished a specific set of objectives. Park \&Chong (2000).

Salem (2009) stated that the implementation of performance systems has many benefits to the organizations, such as production increase and performance quality boost, where the performance elements or factors represent by business requirements identification, work hours, work quality, work cost, and completion time, where the performance influence by a number of internal and external factors, that include:

- Technical factors: it includes technical development and advancement, raw materials, organizational structure, and work methods and techniques. Arabi (2012).

- Human factors: it includes actual ability of work performance, and it consist of knowledge, education, and experience, in addition to the training, skill and personal capability that contain the desire to work, and determine through the physical and social working conditions, needs and desires of individuals, and the demographic factors. Salem (2009).

\subsection{Conceptual models}

Thabit \& Jmealy (2017) conducted a study that aimed to identify the impact of using IT infrastructure on the performance of human resources at the public universities, and also to identify the statistical differences in employees' trends in the use of IT, according to the demographic variables. Study arrived at the existence of relationship between the use of technological infrastructure and human resource performance, and the non-existence of differences attribute to the sex and qualifications variables, and also the non-existence of significant differences due to the age, years of experience, and job category variables. Jiraporn, et al. (2017) conducted a study on a sample of (204) that aimed to determine the impact of processes engineering management on the organizational performance and supply chain collaboration and identifies a median impact of supply chain collaboration between the processes engineering management and organizational performance, by using the structural equation model. The study results showed a significant role for the processes engineering management on the organizational performance and collaborative advantage, and also the existence of indirect impact of supply chain collaboration and collaborative advantage on the organizational performance.

Devika, et al. (2016) conducted a study to find out the factors of processes engineering management by using: processes improvement initiatives, processes centered orientation, and strategical processes alignment in group of Malaysian organizations. The study found that arithmetic mean of processes engineering management in the Malaysian organizations amounted to (3.48), and that processes engineering management contain the factors of process improvement and processes centered orientation. Fakhour (2016) conducted a study that aimed to identify the management processes reengineering in the Jordanian telecom companies, and also identify the impact of processes reengineering on improving the employees' performance standards, such as speed, cost, efficiency, and quality, where the study results showed a medium general level for the processes reengineering, employees' performance, and competitive advantage, the existence of processes' reengineering effect on improving the performance level, and also the existence of statistically significant relationship between the processes reengineering dimensions and performance dimensions to achieve the competitive advantage.

Alwan (2015) conducted a study that aimed to enhance the theoretical underpinnings of quality costs and processes reengineering, show its importance in achieving the competitive advantage of the general Wasit Company for textile industries, and state the importance of using quality costs and processes reengineering to improve the competitive position. The study found that using quality cost method with the processes reengineering help to manage the economic resources of organization more efficiently and achieve the competitive advantage. Saad (2015) conducted a study that aimed to find out 
the implementation level of processes reengineering; from the standpoint of employees at Irbid District Electricity Company, Jordan (IDECO), identify the level of customer satisfaction about company's services, from customers point of view, and also identify the impact of management processes reengineering on the customer satisfaction level at IDECO. The study results showed a high implementation level of processes reengineering, medium level of customers' satisfaction, and the existence of direct effect for the processes reengineering on the level of customer satisfaction.

Rahahleh (2014) performed a study that aimed to clarify the concept of processes reengineering in the Jordanian logistic companies and sees its impact on building and improving the competitive advantage. The study results showed high level of awareness about the concept of processes reengineering in the Jordanian logistic companies, and a big role for information technology on the processes and human resources reengineering. It also showed that concepts and principles of reengineering include focusing on customer and providing the service, which increase the competitive capabilities of logistic institutions. The study of Khudair (2013) aimed to identify the relationship between reengineering success factors and the competitive advantage of industrial organizations. The study arrived to a number of results, and the most important were: the availability of reengineering implementation requirements, and the existence of significant correlation between the reengineering leadership, information technology, human resources rehabilitation, organizational structures flexibility, and the competitive advantage.

Tagaldin (2013) held a study that aimed to identify the processes reengineering and its role in improving the performance of Sudanese banks. The study arrived at a number of results, and the most important were: the existence of positive relationship between the use of information technology and performance effectiveness, and also a positive relationship between the organizational structure and performance efficiency or effectiveness. Amanquah \& Kofi (2013) performed a study that aimed to discover the impact of information technology on processes reengineering, and also identify the impact of human resources management on the success of processes reengineering at Ghana commercial bank. The study found a relationship between the investment increase in knowledge technology and the increase in operating profit of the bank, it found non-participation of all employees in the processes reengineering, and it also found a need to use the appropriate leadership style that believes in participation and partnership.

Goksoy, Ozsoy \& Vayvay (2012) did a study that aimed to focus on processes reengineering, as a tool for managing the organizational change in multinational Turkish company, and the study results indicate that most important success factors for implementing the processes reengineering is the commitment of senior management, in addition to the human resources empowerment, effective communications, teamwork, customer focus, and the agreement of processes reengineering strategy with the corporate strategy. Asmare (2012) conducted a study to determine the impact of processes reengineering on the performance of public sector organizations in Ethiopia. The study results showed that processes reengineering develop the organizations' processes and the organizational performance, where the processes reengineering explained (54\%) from the differences in organizational performance and in order to implement the processes reengineering, it's necessary to provide the required capabilities and resources for the implementation and overcome its problems. Ababneh (2012) conducted a study to determine the impact of business reengineering on the employees' performance at the Jordanian customs, where the study found a medium level of processes reengineering, a high level of employees' performance, and also found a statistically significant impact of processes reengineering on the employees' performance.

Majali (2012) conducted a study to determine the impact of strategic planning factors on the management reengineering process at the Saudi Telecom company (STC). The study arrived at a number of results, and the most important were: the existence of an impact for the strategic planning factors on the management reengineering process at the STC, where the organization's mission variable took the first rank with its impact on the following reengineering dimensions: the senior management commitment, communication, willingness to change, empowerment, and organizational culture. 


\section{Research methodology}

\subsection{Study Community and Sample}

The study community consists of (1293) workers employed at (17) branches, according to SCC official reports for the year 2015. A simple-random sample was chosen from the study community, the researcher distributed (420) questionnaires, with regard to employees at all levels, and (402) of those returned questionnaires were received at (95\%) return rate. Only (12) questionnaires were dismissed for being invalid for statistical analysis.

\subsection{Study instrument}

The researcher reviewed the theoretical background and previous studies about business process management and employee job performance. The researcher also reviewed many questionnaires that used in the previous studies and designed one that reflects business process management and employee performance. The parts of the questionnaire are:

Part one: background information: - where respondents were asked to indicate their gender, age, level of education, job title, and experience.

Part two: dimensions of the study which are:

The first dimension (independent variable): business process management which contains (24) items. contain the secondary dimensions: - items from ( $\mathrm{H} 1$ to $\mathrm{H} 6)$ related to strategic alignment, items from (H7 to H12) related to information technology, items from (H13 to H18) related to process improvement, and items from (19 to 24$)$ related to employee involvement.

The second dimension (dependent variable): job performance which contains the fifteen items from (H25 to H34). The participants were asked to identify the degree of their agreement with each item in the second and third sections of the study, using five-point Likert scale $(5=$ strongly agree, $4=$ agree, $3=$ neutral, $2=$ disagree, and $1=$ strongly disagree). The scale was calculated through the following formula: The highest point of the scale (5) - the lowest point of the scale (1)/ the number of required categories $(3)=1.33$. Thus, 1.33 was added to the end of each category, so that the categories and the degree of agreement became as follows (from -1.00 to less than $2.33=10 w$ ) and (from 2.33 to 3.66 medium) and (from 3.67 to 5.00 = high).

\subsection{Study Validity and Reliability}

Face validity: this implemented in the present study in two phases: First, the questionnaire sent to a pilot sample of (20) workers from different managerial level to assess the clarity of the questionnaire. Second, the questionnaire was reviewed by (9) referees from among the faculty members at Jordanian universities, and some items were adjusted based on their recommendations.

Instrument reliability: the current implemented Cronbach's Alpha measures the reliability of measurement in similar research. Cronbach's Alpha coefficient value of all dimensions of the study is (91\%).

\section{Results \& Discussion}

\subsection{The results related to the research questions}

The results related to first question, what is the awareness degree about the concept of BPM and its components at the SSC, from the standpoint of employees?

To answer this question, the arithmetic mean and standard deviations were calculated for the study sample members' estimates, about the BPM level and its dimensions for the SSC employees, as shown in table (1):

\begin{tabular}{l|l|l|l} 
Dimension & Arithmetic mean & STDEV & Level/ Degree* \\
\hline Strategic alignment & 3.62 & .61 & Medium \\
\hline Information technology & 3.72 & .59 & High \\
\hline Processes improvement & 3.71 & .56 & High \\
\hline Employees involvement & 3.81 & .52 & High \\
\hline Business processes management & 3.71 & .40 & High
\end{tabular}

Table (1) Arithmetic means and standard deviations for the study sample members' estimates of BPM

It noticed from the table above that assessment level of BPM, as a whole from the standpoint of study sample members is (high) with an arithmetic mean of (3.71). Moreover, employees' involvement 
came in the first rank with an arithmetic mean of (3.81) at a high degree, then IT came after employees' involvement with high degree and an arithmetic mean of (3.72), processes improvement also came in the third rank at high degree and an arithmetic mean of (3.71), and finally strategic alignment came in the fourth place with an arithmetic mean of (3.62) and a medium estimation degree. This result indicates a high degree or level of awareness for the concept of processes reengineering at the Social Security Corporation, there is a role and a great concern in human resources involvement and incorporation, where they express it in a proper and scientific way. There's also a very important role of IT in processes reengineering, and the concepts and principles of BPM are factors that lead to increased employees' job performance. This result agrees with the result of Devika, et al. (2016) study, and the study result of Goksoy, et al. (2012).

The results related to second question, what are the levels of employees' job performance at the Social Security Corporation (SSC)? To answer this question, the arithmetic means, and standard deviations were calculated for the study sample members' estimates, about the employees' job performance expressions, as shown in table (2):

\begin{tabular}{|l|l|l} 
Expression & $\begin{array}{l}\text { Arithmetic* } \\
\text { mean }\end{array}$ & STDEV \\
\hline $\begin{array}{l}\text { The executive work programs are formulated according to } \\
\text { the plan }\end{array}$ & 3.70 & 0.38 \\
\hline $\begin{array}{l}\text { I accomplish the mandate work at the require accuracy and } \\
\text { speed }\end{array}$ & 3.94 & 0.43 \\
\hline $\begin{array}{l}\text { I know the required work programs on my level of } \\
\text { organizational units }\end{array}$ & 3.56 & 0.27 \\
\hline $\begin{array}{l}\text { I consider myself able to communicate effectively and team } \\
\text { work spirit }\end{array}$ & 3.59 & 0.52 \\
\hline I prepare and write work reports appropriately & 3.45 & 0.45 \\
\hline I participate in work procedures development & 3.24 & 0.63 \\
\hline I am able to organize my job and control it & 3.70 & 0.58 \\
\hline $\begin{array}{l}\text { I have the ability to tolerate the work pressure and } \\
\text { maintain levels of achievement }\end{array}$ & 3.85 & 0.62 \\
\hline $\begin{array}{l}\text { I participate in transferring the knowledge and expertise to } \\
\text { colleagues }\end{array}$ & 3.70 & 0.63 \\
\hline $\begin{array}{l}\text { I consider myself able to treat the service recipient tactfully } \\
\text { and courteously }\end{array}$ & 3.40 & 0.43 \\
\hline Job performance as a whole & 3.61 &
\end{tabular}

Table (2) Arithmetic means and standard deviations for study sample members' estimates on job

It notices from table (2) the estimate of job performance level as a whole, from the standpoint of study sample members is medium, with an arithmetic mean of (3.61), where the expression (26): "I accomplish the mandate work at the require accuracy and speed" came in the first place, with an arithmetic mean of (3.94) and high estimation degree, and the expression (32): "I have the ability to tolerate the work pressure and maintain levels of achievement" came secondly, with an arithmetic mean of (3.85) at high degree, while the expression (30): "I participate in work procedures development" came in last place, with an arithmetic mean of (3.24) and a medium estimation degree. This result indicates the existence of concern and interest at (SSC) to develop the capabilities of staffs and employees in the various areas, in order to improve their knowledge level, and enhance their level and quality of services provided to the public. This result agrees with the Fakhouri (2016) study, and the study result of Goksoy, et al. (2012).

\subsection{Study hypotheses testing}

Multiple linear regressions were used to explore the presence of a statistically significant effect of the independent variables on the dependent variable at the significance level $(a \leq 0.05)$. Upon inserting the independent variables into the multiple linear regression analysis. Table (3) shows that BPM has a predictive power and is statistically significant. 


\begin{tabular}{l|l|l|l|l|l|l|l|l}
$\begin{array}{l}\text { Source of } \\
\text { variance }\end{array}$ & $\begin{array}{l}\text { Sum of } \\
\text { squares }\end{array}$ & DF & $\begin{array}{l}\text { Mean of } \\
\text { squares }\end{array}$ & R & $R^{2}$ & $\begin{array}{l}\text { Adjusted } \\
R^{2}\end{array}$ & F-value & Sig. \\
\hline Regression & 88.125 & 4 & 22.031 & 0.867 & 0.752 & 0.749 & 286.662 & $.000(\mathrm{a})$ \\
\hline Residual & 29.128 & 379 & 0.077 & & & &
\end{tabular}

Table (3) Multiple linear regressions

3Table (3) shows that BPM had statistically significant effects on job performance, multiple correlation coefficient value was (.867), and the $\left(\mathrm{R}^{2}\right)$ was (.752), and the value of adjusted $\left(\mathrm{R}^{2}\right)$ was $(.749)$, which indicates that business process management was capable of accounting for $(74.9 \%)$ of the changes in the dependent variable (job performance). This result agrees with the study results of (Rahahleh, 2014; Fakhouri, 2016 \& Jiraporn, et al., 2017).

\begin{tabular}{l|l|l|l|l|l}
\multirow{2}{*}{ Model } & \multicolumn{2}{|l|}{$\begin{array}{l}\text { Unstandardized } \\
\text { Coefficients }\end{array}$} & $\begin{array}{l}\text { Standardized } \\
\text { Coefficients }\end{array}$ & T & \multirow{2}{*}{} \\
\cline { 2 - 5 } & $\mathrm{B}$ & Std. Error & Beta & & \\
\hline (Constant) & .601 & 0.141 & & 4.252 & .000 \\
\hline Strategic alignment & .341 & .046 & .274 & 7.487 & .000 \\
\hline Information technology & .123 & .043 & .094 & 2.891 & .004 \\
\hline Process improvement & .150 & .036 & .494 & 12.321 & .000 \\
\hline Employees involvement & .528 & .041 & .131 & 3.484 & .001
\end{tabular}

Table (4) The significance of standardized and un-standardized multiple linear regression coefficient The table (4) shows:

-The existence of a statistical significance for the constant of the multiple linear regression formula, in which the value of $(t)$ was $(4.252)$ with a statistical significance of $(0.000)$, which is below the level $(a \leq 0.05)$ and indicates the significance of the constant.

- The presence of a statistical significance for the coefficient of the multiple linear regression formula related to the independent variable strategic alignment, where the value of $(t)$ was (7.487), with a statistical significance of (0.000), which is below the significance level $(a \leq 0.05)$, and suggests the rejection of the null hypothesis and acceptance of the alternative hypothesis, which states "there is statistically significant effect at $(a \leq 0.05)$ for the strategic alignment on job performance at the Social Security Corporation".

- The presence of a statistical significance for the coefficient of the multiple linear regression formula related to the independent variable IT, where the value of $(t)$ was $(2.891)$, with a statistical significance of $(0.000)$, which is below the significance level $(a \leq 0.05)$, and suggests the rejection of the null hypothesis and acceptance of the alternative hypothesis, which states "there is a statistically significant effect at $(a \leq 0.05)$ for the IT on job performance at the Social Security Corporation". This result agrees with the study results of (Thabit \& Jmealy, 2017; Tagaldin, 2013).

- The presence of a statistical significance for the coefficient of the multiple linear regression formula related to the independent variable process improvement, where the value of ( $t$ ) was (12.321), with a statistical significance of $(0.000)$, which is more than the significance level $(a \leq 0.05)$, and suggests the acceptance of the null hypothesis, which states "there is no statistically significant effect of ( $a \leq 0.05)$ for the process improvement on job performance at the Social Security Corporation". This study aligns with the study of Devika, et al. (2016).

- The presence of a statistical significance for the coefficient of the multiple linear regression formula related to the independent variable employees involvement, where the value of ( $t$ ) was (3.484), with a statistical significance of $(0.000)$, which is more than the significance level $(a \leq 0.05)$, and suggests the acceptance of the null hypothesis which states "there is no a statistically significant effect $(a \leq 0.05)$ for employees involvement on job performance at the Social Security Corporation". This study result aligns with the result of Amanquah \& Kofi (2013). 


\section{Study conclusions \& recommendations 5.1 Study Conclusions}

The analysis of data obtained, through the study tool led to a number of important conclusions, which will hopefully enrich the previous literature, open future prospects for the researchers and scholars, and help the SSC to cope with the changing business environment circumstances, the most distinguished conclusions are:

- The degree of BPM estimation is at high level, where the dimensions of IT, processes improvement, and employees involvement came at high degree of estimation, and came after the strategic alignment of medium estimation degree. These findings suggest the awareness of study sample to the importance of BPM in the work of SSC.

- The estimation degree of job performance level is medium. In order to increase the performance level, it must develop work procedures and prepare business reports.

- The study arrived at the existence of statistically significant impact of BPM on the job performance, where this result indicate that BPM achieve significant improvements in the performance measurements or indicators, such as cost, quality, service, and speed, in addition to the fact that work and processes flow analysis, and the activities analysis inside the organization increase the job performance and the organization efficiency.

- The study arrived at the existence of statistically significant impact of the strategic alignment dimension on the job performance, where this result indicate that strategic alignment considers one of the basic elements or factors for implementing BPM, with the fact that it refers to the longterm goals, it takes customers' needs into consideration, and it care about the internal characteristics of organizations. In addition, the strategic alignment includes the development of specific strategies and plans to maximize the value of processes' design.

- The study arrived at the finding of statistically significant impact of IT dimension on the job performance, where IT plays an important role in the BPM, and it's possible to develop it as part of the improvement and implementation of business processes, and link organization with the environment.

- The study arrived at the existence of statistically significant impact of processes improvement dimension on the job performance, where business processes management focus on the continuous development, instead of focusing on the rational development of processes, and it also use methods and techniques to support the changes in business processes and encourage employees to participate in the change and development processes.

- The study also arrived at the existence of statistically significant impact of employees involvement dimension on the job performance, where the participating Individuals in the processes implementation consider one of the important assets of any organization, the senior management must be committed to the employees empowerment, use the appropriate management method and style to improve the organizational performance, and increase employees' participation.

\subsection{Study Recommendations}

The study recommends SSC to adopt strategic objectives, by providing a distinct social security's and insurance services, to meet the expectations and needs of the participants, retirees, and society, prepare a secure framework for the optimal method of communication with partners, provide a high level of services, develop cooperation and communication ways and channels with the public, and listen to their opinions, suggestions, and complaints.

Increase the concern and interest about IT and provide the electronic services, in order to improve the level of service provided to the public, achieve the superiority service, save time, effort, and cost, and increase the efficiency and transparency of services provided to the public.

Make recommendations to the managerial leadership at the SSC to focus on developing organizational structures of its branches, link it to databases, and develop a number of methodologies and approaches that contribute to the development of SSC work methods, such as service superiority, creativity, and innovation to improve the quality of work. 
Future studies are invited to add any modified variables or intermediary variable to the current study model, such as job or work design, and organizational justice and equality, or personal variables. Researchers need to check and verify the findings of this study in other sectors, such as telecommunications, and make efforts and attempts to implement the study model at other sectors, such as insurance and services, to give more dependability and reliability to the study.

\section{Study limitations and scope for further research}

The major limitation of this study was the small sample size of the respondents, where a larger sample size would validate the statistical findings better. Also, another constraint or limitation was that the respondents were all from only one city and not spread across the country.

\section{References}

Ababneh, Kalthoum (2012). The extent of the application of engineering processes and their impact on the performance of employees in the Jordanian customs department from their point of view. Unpublished master thesis. Yarmouk University.

Ali, N., Payan, R., Afshin, M., Hamidreza, N., Mohammad, R. (2013). Methods and approaches in organizational reengineering. Interdisciplinary Journal of contemporary research in business. 5(2), 635-643.

Alwan, Marwa (2015). Integration of process re-engineering and total quality costs to achieve competitive advantage. Al-Kout journal of economic and administrative sciences. 17, 400-417.

Amanquah. B \& Kofi. A (2013). Business process reengineering (BPR) in the financial services sector: A case study of Ghana commercial bank (GCB) limited. European journal of business and management. 5(29).59-66.

Arabi, Attia (2012). The impact of the use of information technology on the performance of employees in the local bodies - a field study in the university of Ouargla, journal researcher. number (10). University of Qasidi Marbah Ouargla, Algeria.

Asmare, E. (2012). The effect of business process reengineering on public sector organisation performance: a developing economy context. Unpublished doctoral thesis. RMIT University.

Chang, J. (2006). Business process management systems, Taylor and Francis Group, New York, NY.

Chen, I \& Paulraj, A. (2004).Towards a theory of supply chain management: the constructs and measurements, Journal of operations management, 22(2). 119-150.

Davenport, T. (1993). Process innovation: reengineering work through information technology, Harvard business school press, Boston, MA.

Decenzo. D \& Robbins. S(2010). Human resource management (10 th ed). John Wiley \& Sons, Inc.

Devika, N, Sharifah, L ,Syed A., (2016).Measuring Business Process management using business process orientation and process improvement initiatives, Business process management journal, 22 ( 6).1069-1078.

Khudair, Fairuz (2013). The Role of business process reengineering in achieving the competitive advantage of industrial organizations case study in the ready made garments factory in Najaf. Al Ghiri journal of economic and administrative sciences. 9, 95-116. University of Kufa.

Fakhouri, Haneen (2016). The impact of the re-engineering of administrative processes on the performance of employees as a means to achieve competitive advantage in the telecommunications sector. Unpublished master thesis. Yarmouk University.

Goksoy, A., Ozsoy, B. \& Vayvay, O. (2003). Business process re-engineering (BPR): Strategic choice, global advanced research journal of management and business studies, 1(7). 210 -216.

Hammer, M. \& Champy, J. (1993). Re-engineering the corporation: a manifesto for business revolution, New York.

Thabit, Ahmed \& Jmealy, Ahmadi (2017). The use of IT infrastructure and its impact on the performance of human resources in public universities. A field study at the University of Diyala. Journal of accounting and financial studies. 12(38). 236-263.

Hung, R. (2006). Business process management as competitive advantage: A review and empirical study. Total quality management \& business excellence. 17 (1), 21-40.

Hilal, Mohamed Abdel Ghani. (2009). Thinking and strategic planning. Development center for development and publishing. Cairo.

Ismail, Ramah (2010). Impact of workers' competence on their performance in the Malaysian, BEH - Business and,+ 2 (2). 26-52.

Juratory. P, Christos. B, James D. Bannock, K. Pawer. S. (2017). Business process management and supply chain collaboration: effects on performance and competitiveness. Supply chain management. 22 (2), 107-121.

Kohlbacher ,M \& Hajo A. R, (2013). The effects of process-oriented organizational design on firm performance, Business process management journal. 19 (2).245-262. 
Kung, P. and Hagen, C. (2007). The fruits of business process management: an experience report from a Swiss bank. Business process management journal. 13 (4). 477-487.

Majali, Amal (2012). The impact of strategic planning elements in the process of reengineering the administrative processes of STC. Jordanian journal of business administration.1 (8) 495-521.

Nadarajah, D. \& Kadir, S. (2014). A review of the importance of business process management in achieving sustainable competitive advantage. The TQM journal, 26 (5). 522-532.

Neubauer,T. (2009).An empirical study about the status of business process management. Business process management journal. 15 ( 2) pp.166-183.

Paim, R., Caulliraux, H., \& Cardoso, R. (2008). Process management tasks: a conceptual and practical view. Business process management journal. 14 (5). 694-723.

Park.J \& Chong.J(2000). A comparison of absolute and relative performance appraisal systems. International journal of management . 423-429.

Rahaleh, Abdul Razzaq (2014). Business reengineering as a means to achieve competitive excellence in Jordanian service companies. Blida university, Economic sciences and human resource development, Algeria. (10), 36-52.

Rhee, M., \& Mehra, S. (2006). Aligning operations, marketing, and competitive strategies to enhance performance: An empirical test in the retail banking industry. Omega, 34(5), 505-515.

Rosemann, M \& Brocke.v.(2010). The six core elements of business process Management, in J vom Brocke and M Rosemann (eds.), Handbook on business process management, Springer, Heidelberg, 1, 3-16.

Saad, M (2015). The effect of reengineering administrative processes on customer satisfaction level Irbid governorate company as a case study. Unpublished master thesis. Yarmouk University.

Salem, Muayad (2009). Human resources management. Athraa Publishing \& Distribution, Amman, Jordan.

Social security corporation (2015). Sustainability report of the social security corporation. General organization for social security, Amman: Jordan.

Smart, P., Maddern, H. \& Maull, R (2009).Understanding business process management: implication for theory and practice. British journal of management. 20 (4). 491-507.

Sotiris, Z.(2000).Business process re-engineering BPM. Report provided for the EC funded project.

Taj aldin, Fakhr al-Din. (2013). Reengineering administrative processes and their role in improving administrative performance. Unpublished PhD dissertation, Sudan university of science and technology, Sudan.

Trkman, p. (2010). The critical success factors of business process management. International journal of information management. 30 .125-134.

Zairi, M. (1997).Business process management: a boundary less approach to modern competitiveness". Business process management journal. 3 (1). 64-80. 